\title{
DIÁLOGO COM MOACIR GADOTTI NO INSTITUTO PAULO FREIRE
}

\author{
DIALOGUE WITH MOACIR GADOTTI IN PAULO FREIRE'S INSTITUTE \\ DIALOGO CON MOACIR GADOTTI EN EL INSTITUTO PAULO FREIRE
}

\author{
Ivanio Dickmann * \\ ivanio.dialogar@gmail.com
}

\begin{abstract}
REVISTA PEDAGÓGICA
Revista do Programa de Pós-graduação em Educação da Unochapecó | ISSN 1984-1566 Universidade Comunitária da Região de Chapecó | Chapecó-SC, Brasil Como referenciar este artigo: DICKMANN, I. Diálogo com Moacir Gadotti no Instituto Paulo Freire. Revista Pedagógica, Chapecó, v. 18, n. 38, p. 255-258, maio/ago. 2016. DOI: http://dx.doi.org/10.22196/rp.v18i38.3405
\end{abstract}

A minha tarefa estratégica na função de presidente da Cooperativa Habitacional Central do Brasil-COOHABRAS me oportunizou um dos encontros mais marcantes de minha vida: um diálogo com o professor Moacir Gadotti, no Instituto Paulo Freire (IPF), no dia 5 de julho de 2016.

Como sou Historiador de formação, vou ousar fazer este texto em forma de história para que o leitor tenha a compreensão da grandeza deste encontro para mim e para o cooperativismo habitacional autogestionário, visto que este tem como um de seus pilares a Educação Popular inspirada em e por Paulo Freire.

Sem mais delongas, vamos ao que importa.

Depois de um longo contato com a secretaria do IPF, agendei uma conversa com o professor Gadotti às 9 horas da manhã. Da minha casa até o Instituto, leva-se em torno de 1 hora em fluxo normal de trânsito. Eu sou gaúcho, e moro em São Paulo há cinco anos e meio. Já sei que o deslocamento na "selva de pedra" no horário anterior ao combinado é complicado.

Para não me atrasar, levantei-me cedo - depois de uma noite quase insone, devido às expectativas que minha mente teimava em criar e em recriar a cada minuto -, e resolvi tomar o metrô já que, para minha sorte, o IPF fica razoavelmente próximo da última estação da Linha 2 - Verde, do Metrô de São Paulo. Eu moro no lado oposto a esta linha; assim, não teria de fazer baldeação. Bastaria que eu embarcasse na Estação Alto do Ipiranga, e deixasse a que composição me conduzisse (obviamente, em pé e apertado entre os demais usuários) até a Estação Vila Madalena. E isso demoraria uns 26 minutos.

Da Estação Vila Madalena até o ponto de encontro, são mais 1,5 quilômetros, ou seja, equivalente a 20 minutos de caminhada ou 6 minutos de táxi. Optei pelo táxi, pois estava levando comigo uma mochila cheia com todos os livros da COOHABRAS - para presentear o Instituto e quatro livros meus 


\footnotetext{
Graduado em História pelo Centro Universitário Assunção (UNIFAI) de São Paulo. Mestrando em Serviço Social pela Pontifícia Universidade Católica de São Paulo (PUC-SP). Idealizador, fundador e presidente da Cooperativa Habitacional Central do Brasil (COOHABRAS).
}

para presentar Moacir Gadotti e a secretária, que havia gentilmente me atendido e marcado a reunião - e, ainda, com um tripé - para poder fazer um vídeo com o professor, uma pequena entrevista, como eu chamei nos $e$-mails que trocara com a secretária, embora esta ainda não tivesse confirmado se eu poderia fazer a gravação. Eu resolvi me prevenir, levando o utensílio.

Desci na Vila Madalena com folga no horário. Eram 8 h2omin. Fui ao ponto de táxi; porém, não havia nenhum carro disponível. Esperei. E, enquanto aguardava pelo táxi, dei uma olhada no meu $e$-mail na esperança de que haveria a confirmação de poder gravar a entrevista, não para fazer valer o esforço físico de carregar o tripé, mas pelo valor que eu via na oportunidade de ter uma gravação em vídeo com o professor Gadotti.

Qual foi a minha surpresa? Ao abrir meu $e$-mail, vi que, há poucos minutos, às $8 \mathrm{~h} 32 \mathrm{~min}$, o professor havia respondido por escrito, ele mesmo, às perguntas que eu mandara previamente, e que, se eu quisesse, depois, eu poderia gravar um vídeo. Eu não sabia se chorava ou se gargalhava! Estava radiante... Olhava para os lados, e ria sozinho. Não acreditava que estava lendo aquelas palavras. Mas, era verdade!

Enfim, um táxi! Entrei, disse, “de cabeça”, o endereço do Instituto Paulo Freire:

- Por gentileza, amigo, Rua Cerro Corá, 550.

Eu já havia ido uma vez até o IPF em 2011. Mas, agora, a visita tinha outro significado. Representava a partilha de um avanço no campo da Educação Popular junto ao cooperativismo habitacional autogestionário. A reunião tinha o intuito de contar ao IPF sobre a caminhada da COOHABRAS, como uma intervenção pedagógica no campo da falta de moradia para famílias de baixa renda. Eu tinha a tarefa de informar, ao presidente do instituto que preserva a memória e o legado de Freire, o quanto a Educação Popular tem contribuído para a conscientização das famílias organizadas pelo cooperativismo habitacional autogestionário, com o fomento e o apoio pedagógico da nossa cooperativa.

Entrei no prédio, e subi as escadas até o segundo andar. Fui encaminhado diretamente para a sala da presidência, onde fui acolhido pela Camila Téo, secretária que havia marcado a entrevista. A sala do professor Gadotti é contígua à da secretaria, dividida apenas por uma parede, o que possibilita o diálogo entre ele e a moça. Após um rápido cumprimento à Camila, fui por ela conduzido para a presença do professor Gadotti, que já me esperava.

Abraçamo-nos, e sentamos frente a frente. Farei uma rápida digressão aqui. E peço que me perdoe as sentimentalidades.

Explico-me: eu não tive a oportunidade de conhecer o professor Paulo Freire em vida. Ele faleceu em 1997. Eu li sua obra Pedagogia do Oprimido pela primeira vez em 2005. Quando me situei historicamente sobre essa situação, tomei para mim que o sucessor de Freire era Gadotti, 
pela caminhada conjunta que ambos traçaram na luta pela educação no Brasil. Veja, leitor, isso somente funciona na minha mente, pois não há essa transferência de legado na prática. É, portanto, a fantasia que eu alimentava mentalmente. Então, compreenda, estar em frente ao professor Moacir Gadotti, naquele momento, era o mesmo que estar diante de Paulo Freire. Você entende agora porque eu não dormi na noite anterior ao encontro?!

Voltemos à razão. O professor Gadotti foi muito gentil comigo. Chamou para acompanhar nosso diálogo uma especialista em cooperativismo do IPF, que teve experiência com alguns trabalhos em cooperativas. Foi um diálogo fluído e agradável. As sintonias políticas e pedagógicas eram evidentes. Eu falava um pouco, e me deleitava ouvindo o mestre. Mais longamente, em certo momento, descrevi o que estávamos fazendo na COOHABRAS e na Rede Nacional de Habitação Solidária, utilizando a Educação Popular e a obra de Paulo Freire como instrumentos de libertação das famílias sem casa no Brasil.

Eu fazia um esforço tremendo para manter a concentração e não deixar nenhum detalhe de fora de minha narrativa eloquente, dando a devida importância ao processo pedagógico como caminho para a moradia cooperativa. $\mathrm{O}$ professor Gadotti me interrompeu brevemente, e disse que o Paulo (é assim que ele trata o Professor Paulo Freire) ficaria muito feliz se tivesse conhecido uma experiência de Educação Popular no campo da moradia para as famílias mais necessitadas. Eu me desconcentrei totalmente... Minha mente criou - em uma fração de segundo - mil cenas do mestre Paulo Freire verbalizando, de sua forma mansa e sincera, essa frase que foi dita por Gadotti. Quando, por fim, recobrei a consciência, resolvi encerrar a contação dos detalhes, pois eu já não tinha mais o que dizer diante dessa constatação transcendental. Eu estava pleno... As lágrimas corriam em minha face, sem nenhum pudor. Não consegui mais falar. Emocionei-me com a gentileza do professor Gadotti, que notou minha emoção e sorriu para mim.

Tudo estava em seu devido lugar. Eu estava como que nas nuvens. Então, suspenso em minha emoção, contive-me e ouvi as reflexões do professor Gadotti, as quais reforçavam a necessidade de fazer dos Círculos de Cooperação das cooperativas habitacionais um lugar de crítica ao mercado excludente.

Gadotti finalizou sua fala, mencionando que colocava o IPF à nossa disposição, embora estivessem operando com uma equipe mais reduzida em razão da conjuntura atual. Eu agradeci, e convidei-o para, se possível, estar presente em nossos próximos cursos de Educadores Populares.

Ao final, partimos para a troca de presentes. Eu entreguei todo o Kit Pedagógico da COOHABRAS e a nossa última publicação, intitulada $A$ Questão da Habitação Popular. Também fiz questão de entregar ao professor Gadotti uma cópia da segunda edição de Primeiras Palavras em Paulo Freire, ambas de minha autoria em conjunto com meu irmão, Ivo Dickmann. 
Fui presenteado com uma cópia do volumoso e valoroso livro Paulo Freire - Uma Biobibliografia, organizado pelo professor Moacir Gadotti, uma das obras mais relevantes sobre Freire das quais eu tenho conhecimento. Mas o que me deixou mais lisonjeado foi receber, das mãos de Moacir Gadotti, uma cópia do Manuscrito da Pedagogia do Oprimido, um livro que fotoapresenta o texto integral digitalizado de Pedagogia do Oprimido - escrito por Paulo Freire, de próprio punho, durante seu exílio no Chile.

$\mathrm{E}$, finalmente, gravei um breve vídeo para encerrar definitivamente nosso encontro. Pedi ao professor Gadotti que não se prendesse às questões enviadas anteriormente, pois eu já as havia lido no $e$-mail, e estava completamente satisfeito com o conteúdo. Pedi que Gadotti deixasse uma mensagem para os Educadores Populares da COOHABRAS e da Rede Nacional de Habitação Solidária. O que ele prontamente aceitou e fez, como se pode constatar no vídeo.

Ao nos despedirmos, o professor Gadotti solicitou que eu fosse conhecer a biblioteca do IPF e as duas bibliotecas do Paulo Freire. Poder ter acesso aos livros manuseados pelo grande mestre da educação brasileira foi, sem dúvida, outra experiência incrível e que deixou minha manhã ainda mais completa.

Eu deixei o Instituto Paulo Freire por volta das 11h3omin com um monte de livros novos e com uma bagagem carregada de mística freireana. O IPF mantém Freire vivo. Quem puder visitar o IPF notará e sentirá o que eu descrevi. Por isso, não vejo a hora de poder ir lá novamente.

Recebido em: 06/09/2016 Aprovado em: 28/09/2016 